\title{
Correction to: Flow of online misinformation during the peak of the COVID-19 pandemic in Italy
}

Guido Caldarelli $i^{1,2,3^{*}}$, Rocco De Nicola ${ }^{3,5}$, Marinella Petrocchi ${ }^{4,3}$, Manuel Pratelli ${ }^{3}$ and Fabio Saracco ${ }^{3}$

The original article can be found online at https://doi.org/10.1140/ s13688-021-00289-4

\section{"Correspondence:} Guido.Caldarelli@unive.it

'Department of Molecular Sciences and Nanosystems, Ca'Foscari University of Venice, Ed. Alfa, Via Torino 155, 30170 Venezia Mestre, Italy

2European Centre for Living Technology (ECLT), Ca' Bottacin, 3911 Dorsoduro Calle Crosera, 30123 Venice, Italy

Full list of author information is available at the end of the article
Correction to: EPJ Data Science (2021) 10:34, https://doi.org/10.1140/epjds/s13688-02100289-4

Following publication of the original article [1], it was reported that the Supplementary Information contained text in magenta, which should be printed in black.

The original article [1] has been corrected.

\section{Author details}

'Department of Molecular Sciences and Nanosystems, Ca'Foscari University of Venice, Ed. Alfa, Via Torino 155, 30170 Venezia Mestre, Italy. ${ }^{2}$ European Centre for Living Technology (ECLT), Ca' Bottacin, 3911 Dorsoduro Calle Crosera, 30123 Venice, Italy. ${ }^{3}$ IMT School For Advanced Studies Lucca, Piazza San Francesco 19, 55100 Lucca, Italy. ${ }^{4}$ Institute of Informatics and Telematics, National Research Council, via Moruzzi 1, 56124 Pisa, Italy. ${ }^{5} \mathrm{CINI}$ - National Laboratory for Cybersecurity, via Ariosto, 25, 00185 Roma, Italy.

\section{Publisher's Note}

Springer Nature remains neutral with regard to jurisdictional claims in published maps and institutional affiliations.

Published online: 29 July 2021

\section{References}

1. Caldarelli G, De Nicola R, Petrocchi M et al (2021) Flow of online misinformation during the peak of the COVID-19 pandemic in Italy. EPJ Data Sci 10:34. https://doi.org/10.1140/epjds/s13688-021-00289-4

\section{Springer}

(c) The Author(s) 2021. This article is licensed under a Creative Commons Attribution 4.0 International License, which permits use, sharing, adaptation, distribution and reproduction in any medium or format, as long as you give appropriate credit to the original author(s) and the source, provide a link to the Creative Commons licence, and indicate if changes were made. The images or other third party material in this article are included in the article's Creative Commons licence, unless indicated otherwise in a credit line to the material. If material is not included in the article's Creative Commons licence and your intended use is not permitted by statutory regulation or exceeds the permitted use, you will need to obtain permission directly from the copyright holder. To view a copy of this licence, visit http://creativecommons.org/licenses/by/4.0/. 